\title{
Remontar as mídias: o pensamento imagético de Harun Farocki
}

\author{
Luís Flores \\ Doutorando; Universidade Federal de Minas Gerais, Belo Horizonte, MG, Brasil \\ luisfdf@gmail.com

\section{César Geraldo Guimarães} \\ Pós-Doutor; Universidade Federal de Minas Gerais, Belo Horizonte, MG, Brasil \\ cesargg6@gmail.com
}

\begin{abstract}
Resumo
O cineasta alemão Harun Farocki desenvolveu, ao longo de sua filmografia, uma série de investigações pujantes sobre as imagens técnicas e seus efeitos sobre a vida humana. Ao trabalhar com materiais heterogêneos, provenientes dos mais diversos suportes midiáticos, ele desenvolve reflexões fundamentais que podem ser colocadas ao lado dos principais pensadores da mídia e da técnica no século $X X$, como Friedrich Kittler e Jonathan Crary, e das tecnologias de controle, como Michel Foucault. Voltando-se predominantemente para os condicionamentos e as interseções das tecnologias midiáticas, Farocki elabora um pensamento ímpar no qual elementos ou contextos específicos são reconectados, por meio da montagem cinematográfica, aos circuitos mais amplos que os envolvem. Um pensamento assim constituído permite que as imagens, juntamente às mídias que as promovem, sejam continuamente desmontadas e remontadas, a fim de alcançar uma compreensão mais ampla sobre os seus mecanismos em contextos variados. Neste artigo, partimos da análise de dois filmes do cineasta, A saída dos operários da fábrica (1995) e Videogramas de uma revolução (1992), para demonstrar como esse gesto de remontagem ocorre.
\end{abstract}

\section{Palavras-chave}

Farocki. Montagem. Mídias. Cinema. Técnica. 
"A história se decompõe em imagens, não em histórias"

Walter Benjamin.

\section{Reposicionar as imagens}

Uma mão escreve no caderno, uma televisão transmite cenas de protesto popular. Mostradas em split screen, com duas janelas na mesma tela, essas imagens não possuem, a princípio, nenhuma conexão definida. A voz de Harun Farocki (1944-2014), um dos principais artistas alemães do século XX, vem se sobrepor a elas para dizer: "Mal posso escrever uma palavra, hoje, se não há uma imagem na tela ao mesmo tempo. Na verdade, em duas telas. [...] 0 importante é haver duas imagens que são vistas ao mesmo tempo, uma imagem em relação à outra". Esta é a abertura de Interface (1995), curta-metragem no qual Farocki reflete sobre seu peculiar trabalho com as imagens (e não apenas sobre elas). Com efeito, o método do cineasta afirma a prevalência das relações imagéticas - para, entre e com as imagens - no seu pensamento fílmico. Arriscamos dizer que quase todo filme de Farocki pode ser entendido, sob um prisma brechtiano (DIDI-HUBERMAN, 2009, 2018), como a tentativa de re-posicionar uma imagem específica - seja a de um ator, de uma fábrica ou de um míssil teleguiado - em relação a outras imagens, a fim de identificar a posição que ela assume em um contexto social e político particular (situado no tempo histórico). Ao mesmo tempo, esse processo de elaboração imagética, de montagem e remontagem dos elementos diversos, permite que o cineasta assuma, ele próprio, uma posição determinada sobre as coisas.

Esse gesto de organização do material - disposto em novos arranjos - produz um deslocamento de sentido que implica não apenas o conjunto das imagens reunidas pelo filme, mas também os suportes técnicos dessas imagens, seus dispositivos, e até mesmo os sistemas mais amplos que as estruturam e colocam em circulação no mundo. Colocar juntas "uma imagem em relação à outra" significa, também, colocar "um objeto midiático em relação ao outro" ou, simplesmente, "uma mídia em relação à outra", o que reforça o caráter multimidiático das operações farockianas de (re)montagem. Como reforça Didi-Huberman (2018), se a montagem coloca sempre uma imagem em relação à outra, não se trata nem de produzir uma equivalência simples nem uma oposição entre uma e outra. 
Há uma dimensão fundamentalmente heteróclita no método de montagem farockiano. Provenientes de vários dispositivos midiáticos, as imagens por ele convocadas são investigadas com os próprios dispositivos midiáticos, isto é, por meio deles e também $a o$ lado deles. As máquinas de ver, que produzem e fazem circular as imagens, tornam-se também um objeto de reflexão. Em outras palavras, Farocki nunca se serve do conteúdo de um determinado meio sem levar em conta, minimamente, o seu mecanismo (interior) e a sua interface (exterior), sua posição determinada no interior de um esquema tecnológico ou de uma organização histórica mais ampla, composta por mídias integradas em circuitos (ou linhagens) abrangentes. A começar, é claro, pelo próprio dispositivo do cinema.

Como afirma Nicole Brenez (2014), "Farocki estuda não somente imagens, [...] mas o cinema e o próprio audiovisual, capturados nas suas lógicas inaugurais de instrumentos, dentre outros, da sociedade de controle" (BRENEZ, 2014, p. 218). Ele sabe bem que a capacidade do cinema ou do vídeo de analisar os esquemas de poder das imagens (técnicas) mais recentes não os exime de participarem ativamente da história das tecnologias de controle. Sob esse ponto de vista, ele leva mais adiante a lição godardiana de "[...] total desprezo por todo discurso que tende a definir, a preservar uma 'especificidade' do cinema" (DANEY, 2011, p. 113). Mesmo os seus filmes que não se voltam diretamente para o cinema (ou contra ele) continuam a operar, em algum grau, uma desconstrução estrutural que escava em contextos diversos - da onipresença das câmeras de vigilância aos simuladores militares, passando pelos sistemas de regulação urbana - os conceitos que fundamentam a existência das imagens e quais implicações elas trazem para a as nossas formas de vida em sociedade.

A famosa (e desgastada) máxima mcluhaniana de que "o meio é a mensagem" (MCLUHAN, 1994, p. 7), ou, na formulação irônica do próprio autor, de que o meio é a massagem (MCLUHAN; FIORE, 1996), frequentemente manejada por teóricos conservadores da mídia, não foi levada às suas últimas consequências. Seria melhor afirmar, como o faz Friedrich Kittler (2010, p. 31), que o conteúdo de um meio é sempre um outro meio. Farocki, ao seu modo, conduz uma investigação crítica contínua sobre o funcionamento da imagem técnica, seus dispositivos e sistemas, sempre considerados em termos amplos, com repercussões mecânicas, sensoriais e filosóficas, principalmente quando observados no interior de uma rede tecno-midiática complexa. Não é exagero afirmar que poucos cineastas foram tão longe na sua reflexão cinematográfica sobre a visão midiática, formulando uma verdadeira teoria sobre o olhar na era da reprodutibilidade e da visibilidade técnica. Sem 
esquecer, neste caso, que a palavra teoria, o vocábulo primordial dos filósofos gregos, antes do significado estritamente acadêmico instituído com Platão, trazia significados muito próximos à experiência do cinema, como “[...] 'olhar', 'observar', 'uma festa para os olhos', 'um espetáculo', e até mesmo 'pompa'” (KITTLER, 2010, p. 23-24).

Podemos dizer que a teoria farockiana das imagens traduz as atitudes e abordagens mais importantes do pensamento cinematográfico dos últimos trinta anos, dedicadas a compreender as transformações pelas quais passou nosso olhar diante da profusão inédita de objetos e sistemas midiáticos. Farocki é um pensador que atua em dois campos de investigação da imagem técnica: um, que se volta para o estudo dos condicionamentos produzidos pelas mídias sobre os sujeitos na sociedade da vigilância, como as estratégias de controle do corpo e do espírito e as maquinações dos gestos (questões exploradas por Michel Foucault, 1987; e Jonathan Crary, 2012; 2013). Outro, que se preocupa com a hibridização dos desenvolvimentos midiáticos, as novas possibilidades estéticas do olhar cinematográfico, transformado pelo contato - nem sempre pacífico - com outros dispositivos produtores e difusores das imagens em movimento. É a famosa querela dos dispositivos, como bem a nomeou Raymond Bellour (2012). ${ }^{1}$ Entretanto, esses dois campos de investigação remetem a uma linha unificada de abordagem (filosófica) das imagens: a dos efeitos materiais das mídias sobre agentes humanos e não-humanos, particularmente as mídias ópticas. Esses efeitos podem ser tomados como aqueles produzidos, por um lado, sobre os corpos ou os olhares dos sujeitos, e, por outro lado, sobre as outras mídias existentes no mundo. Neste artigo, iremos abordar, por meio da análise de dois filmes específicos, de que modo essa dupla perspectiva teórica ganha corpo no cinema de Farocki, a partir do momento em que o cineasta converte a imagem cinematográfica em uma potente ferramenta de investigação analítica do mundo e das imagens técnicas que o conformam (BELLOUR, 2002)

A estratégia farockiana de relacionar imagens pressupõe a habilidade singular de manejar dois aspectos privilegiados da montagem cinematográfica: a seleção dos materiais coletados e sua posterior ordenação. Embora adquira traços específicos em cada filme, especialmente quando consideramos o contraste entre as obras de viés ensaístico e os filmes de observação direta, essa montagem carrega constantemente uma parcimônia estilística frente aos materiais convocados, permitindo que eles preservem uma dose da sua

\footnotetext{
10 trabalho de Farocki dialoga com as ideias de Bellour em torno do advento do vídeo, especialmente no que concerne à sua capacidade analítica de se colocar entre outras imagens (BELLOUR, 2002).
} 
autonomia. Esses materiais, vale dizer, quase sempre são produzidos por outros agentes, terceiros, humanos ou maquínicos, sendo muito raros os casos em que Farocki liga a câmera para filmar:

Nada de atores; nada de imagens realizadas por mim; melhor citar coisas que já existem e criar uma nova qualidade documental. Evitar as entrevistas com o sujeito-objeto do documental; deixar todo o incômodo da complexidade aos idiotas dos quais se pretende distanciar (FAROCKI, 2013, p. 298, tradução nossa).

O filme Interface (1995) pode ser entendido como um ponto de inflexão crítica na trajetória do cineasta. Suas obras posteriores - bem como os vídeos e as instalações assumem, com radicalidade crescente, a tarefa de organizar as imagens e os sons de maneiras não convencionais. Essa radicalidade adquire, contudo, um aspecto não ostensivo, pois deriva também da recusa em aderir por completo às lógicas do cinema de autor ou de gênero, atitude visivelmente presente em todo o espectro de sua obra. A dinâmica interna do olhar farockiano, construída por uma peculiar maneira de combinação dos materiais, de ordenação discursiva, de enquadramento ou reenquadramento visual, apresenta uma rigorosa cláusula de modéstia. A esse respeito, Didi-Huberman (2018) apontou com muita acuidade as diferenças que separam as atitudes de Godard e Farocki:

Godard se diz o autor soberano de suas imagens: ele projeta de certa forma sobre o cinema uma concepção de artista que, na verdade, procede diretamente de um estatuto jurídico inventado no Renascimento. Enquanto Farocki se afirma - sem renunciar a suas prerrogativas de autorensaísta - como produtor não exclusivo, não soberano de suas imagens. Como podemos ser o soberano absoluto de coisas que se quer restituir a todos? Quando Godard dá a pensar, ele oferece à admiração seu próprio pensamento, seja ele indiscernível dos múltiplos pensamentos que ele utiliza, cita, recorta ou ainda desvia. Quando Farocki dá a pensar, ele nos oferece uma reflexão, não sobre seu próprio pensamento, mas sobre outra coisa. Godard sempre tem a última palavra sobre suas montagens, Farocki faz questão de nunca ter a última palavra (DIDI-HUBERMAN, 2018, p. 188).

É patente, nesse sentido, o isolamento artístico do cineasta, junto ao fator de distanciamento (ou estranhamento, para reforçar a inspiração brechtiana de seu gesto) que informa não apenas os filmes, como também a própria figura do cineasta. Suas obras 
oferecem pouco ou nenhum apelo no que diz respeito à chamada fruição narrativa ou ao prazer visual que solicitam a identificação do espectador. Constituem, antes, verdadeiros estudos dedicados a elementos ou contextos técnicos determinados, neles apanhando, materialmente, a especificidade da mediação própria da imagem e seus efeitos sobre nossa sensibilidade e nossa compreensão do mundo.

As particularidades do modo com que Farocki elabora seus filmes, e que concede ao seu trabalho uma singularidade que o distingue fortemente de outros cineastas (mesmo aqueles dos quais se aproxima, como Godard ou os Straub, por exemplo), são inseparáveis da multiplicidade de materiais imagéticos convocados pela montagem. Farocki encontra, em seus filmes, uma abertura surpreendente para categorias visuais consideradas "impróprias" no universo do cinema, como registros de câmeras de vigilância, gravações feitas por mísseis teleguiados, trechos de comerciais televisivos, imagens de videogames e simuladores. Essa capacidade de absorção, essa porosidade para as diferentes imagens que circulam no mundo, delineia um círculo sucessivo de experimentações no qual os materiais utilizados acabam por contaminar a organização dos filmes com dinâmicas próprias, oriundas de seus próprios mecanismos internos ou reminiscentes de seus contextos originários. Desse modo, novas formas de articulação audiovisual são engendradas, com abertura ainda maior para aquelas imagens que se desviam, a princípio, dos códigos predominantes de narrativa fílmica.

O fluxo das imagens e dos sons, sua forma de associação, de sucessão, de reação em conjunto, tão distantes da transparência e da ilusão que regem o cinema clássico, também não coincidem por completo com os desvios e as transgressões características do cinema moderno, com sua tendência à fragmentação não-linear. 0 projeto farockiano, sustentado de maneira muito consciente desde seus primeiros filmes, encontra com o tempo uma formulação própria, que parte de um conjunto coerente de referências - Straub-Huillet, Godard e Brecht ${ }^{2}$ - para alcançar uma perspectiva rigorosa, quase intransigente, de desconstrução crítica da imagem "espetacular", da imagem apoteótica do cinema com seus múltiplos desdobramentos midiáticos no mundo do alto capitalismo³

\footnotetext{
2 Dada a amplitude das obras dos artistas envolvidos (Farocki, Straub-Huillet, Godard e Brecht), não podemos, nos limites deste artigo, delimitar todas as correspondências entre seus diferentes projetos. Para melhor compreender suas conexões, sugerimos a leitura de alguns textos (DIDI-HUBERMAN, 2018; ELSAESSER, 2004; FAROCKI, SILVERMAN, 1998).

3 Diferentemente de Vertov, que acoplava a câmera ao olho e ao mundo para produzir revelações e conhecimentos sobre as coisas, Farocki quer buscar, nas câmeras e nas mídias já acopladas ao mundo, um novo conhecimento possível.
} 


\section{Efeitos materiais da imagem técnica}

A primeira imagem que vemos no filme $A$ saída dos operários da fábrica (1995), após a cartela de título e o nome do diretor, é o plano frontal de um galpão capturado com câmera fixa, talvez o galpão industrial mais visto, exibido e discutido da história das imagens em movimento. Desse galpão com duas passagens, uma porta lateral e um imenso portão, sai um pequeno número de homens e uma vasta maioria de mulheres que desaparecem ao final do plano. Nesse momento, uma das folhas do portão se fecha, antes da tela escurecer indicando o término da filmagem. Esse plano, que dura pouco menos que um minuto, é acompanhado de perto por uma voz em off que reflete sobre aquilo que é mostrado, inicialmente, de maneira descritiva, e depois aumentando sutilmente o grau de especulação, sugerindo que talvez esses corpos só estejam ali, inscritos sob a forma de luz, para comprovar que o movimento é um vetor que pode ser reproduzido tecnicamente.

Trata-se, é claro, do célebre filme dos Irmãos Lumière, também conhecido como $A$ saída dos operários da fábrica (1895). Ele será convocado outras vezes no decorrer do filme de Farocki, com um acréscimo de camadas e sentidos advindos não apenas do texto ensaístico, que ouvimos constantemente em voz off, mas, principalmente, da combinação com outras imagens, de naturezas diversas, produzindo diferentes posições ou pontos de vista. Antes de avançar, porém, observemos que esse arquivo utilizado na abertura constitui, justamente, um dos filmes mais consagrados do primeiro cinema, e talvez um dos mais legitimados pela historiografia oficial como integrante do corpus originário da invenção (algo mítica) do cinematógrafo. Essa escolha da montagem demonstra a postura analítica que Farocki assume em relação ao medium, ao dispositivo de fabricação dessas imagens, isto é, o cinema com suas mutações históricas e técnicas.

Além disso, uma vez escurecida a tela, após a primeira visualização do filme dos Lumière, ela volta a se iluminar para fazer aparecer uma imagem, desta vez pausada, da mesma multidão em debandada do galpão. A voz em off dirá: "Desta primeira projeção, fica na memória a pressa dos trabalhadores que saem, como se algo os puxasse. Ninguém fica no recinto da fábrica". Farocki utilizará, ao longo do filme, da força dessa ferramenta analítica para ressignificar a figura do operário em relação ao espaço da fábrica, mostrando que o mesmo lugar designado para o trabalho consiste, no fundo, em um lugar de opressão dos corpos e espíritos, equiparável a uma instituição prisional. 
Talvez os pontos mais marcantes da reflexão do cineasta sejam aqueles que associam as imagens de trabalhadores insubordinados, em momentos de greve ou de tensão, aos extratos publicitários de empresas de segurança, com suas câmeras de vigilância, suas grades intransponíveis, seus sensores de proteção. Retomemos esses momentos. 0 primeiro deles ocorre por volta dos 15 minutos de filme, após uma série de sequências que discutem episódios de conflito motivados pela presença - ou pela ausência - dos trabalhadores nas fronteiras estabelecidas pela fábrica. Após vermos os rostos de alguns operários, por detrás das grades da fábrica, Farocki introduz um pequeno trecho publicitário, com imponentes portões de aço, indicando que há todo um aparato de vigilância e controle dedicado a conter a (suposta) violência dos trabalhadores. Esse insert pode parecer ambíguo, pois fica sem maiores explicações e não chega nem mesmo a ser diretamente comentado pela voz em off. Mas as imagens que o sucedem são esclarecedoras, dando a ver a repressão dos operários e o temor dos patrões diante de uma revolta coletiva: primeiro, o famoso trecho de Tempos modernos (1936), de Chaplin, com os manifestantes na porta da fábrica. Depois, cenas de um filme de 1948, da Alemanha Oriental, que mostra os trabalhadores expulsando a polícia do interior de uma fábrica. "A polícia receia mais a importância dos trabalhadores do que a sua violência", diz o narrador. Logo a seguir, surgem as cenas de um protesto na fábrica da Volskwagen em Emden, onde a direção ameaça expulsar os insubordinados com a ajuda da polícia.

É nesse momento, aos 20 minutos de filme, que vemos o segundo insert dos trechos publicitários. Desta vez, barricadas mecanizadas se levantam do chão, enquanto a voz em off comenta: "Trata-se da proteção da propriedade, medidas para proteger a fábrica". Eles serão seguidos, na montagem, por imagens que testam e demonstram a resistência da tecnologia em questão, essa espécie de barricada automatizada ou muro de vedação. A narração do filme pondera:

Um caminhão é puxado a $80 \mathrm{~km} / \mathrm{h}$ contra a vedação e fica destruído. Também esta fantasia de violência faz do átrio da fábrica um lugar histórico. Recordar greves e fura-greves, ocupações de fábrica e acesso vedado, lutas por salários e justiça, e a esperança relacionada com elas $(A$ saída dos operários da fábrica, 1995).

O que Farocki procura demonstrar - discursiva e imageticamente - é a predominância de um olhar vigilante, de um olhar panóptico, presente em imagens que, a 
princípio, não indicariam mais do que a saída dos trabalhadores da fábrica. Um olhar vigilante que corresponde, na verdade, a toda uma estrutura policial feita para defender os limites da fábrica e fiscalizar os movimentos dos operários, isto é, dos corpos que ocupam os espaços industriais. Algo muito próximo do que encontramos em Michel Foucault (1987) ou Jonathan Crary (2012; 2013), apresentado, aqui, sob a forma das imagens em movimento.

É justamente nesse ponto, porém, que Farocki traz um suplemento crítico para a elaboração do pensamento acerca das técnicas de controle que atravessam a esfera midiática e a dos dispositivos ópticos. Primeiro, ele mostrará cenas do filme The killers (1946), de Robert Siodmak, no qual quatro bandidos disfarçados de operários - quatro operários "falsos" - roubam o montante dos salários no escritório da fábrica. A seguir, a sequência é congelada - e suspensa, para o trabalho da análise - enquanto o narrador comenta as imagens: "A fábrica como cenário do crime. Agora, não são trabalhadores, mas sim bandidos saindo da fábrica". A sequência, agora colocada novamente em movimento, continua até que os bandidos saiam do pátio da fábrica. A montagem introduz, então, um novo material imagético, que suscita uma nova série de reflexões: um plano fixo, aparentemente produzido por uma câmera de vigilância, com o identificador do registro no canto superior esquerdo da tela, mostra dois supostos bandidos que atravessam o quadro de um lado para o outro. Farocki, curiosamente, faz intervenções sonoras e visuais nesse excerto, decompondo a travessia em frames estáticos, fora da ordem natural do movimento, pontuando os frames com sons em crescendo, e, finalmente, incluindo um contorno retangular vermelho, um identificador, sobre uma das pessoas filmadas.

A reflexão sobre a vigilância retorna de imediato: um porteiro, sob a égide de Hitler, caminha pelo pátio de uma fábrica no momento de fechar o espaço, até que chama o vigilante noturno. Ele pergunta sobre um homem desconhecido que se encontra do lado de fora dos portões, mas o vigilante, respondendo que não sabe quem é, manda ele descobrir o que é o estranho quer. 0 cachorro late ameaçadoramente. A cena é concatenada com o terceiro extrato de propagandas de segurança privada. 0 plano de uma câmera de vigilância, em close, faz o seu movimento de um lado para o outro. Um homem observa o monitor televisivo que exibe as imagens gravadas. Uma mesa aperta um botão vermelho na mesa de controle. Esse botão aciona nada mais nada menos do que as imagens do filme dos Lumière outra vez, agora acompanhadas por uma nova camada de comentários, ainda mais complexa: 
Onde antigamente estava situada a primeira câmera, estão hoje milhares de câmeras de vigilância. A câmera detectou uma mulher que dá um puxão na saia de outra antes de cada uma ir para o seu lado. Dá um puxão, mas a outra, pelo visto, não se atreve a fazer o mesmo devido ao olho da câmera. Essa brincadeira é uma ação sem contra-ação. Desse modo, há um desequilíbrio. Desequilíbrio e compensação, é essa a lei do movimento dos filmes (A saída dos operários da fábrica, 1995).

Esse momento do filme designa, de maneira bastante direta, a investida organizada pelo poder capitalista para controlar os gestos dos trabalhadores nas fábricas, por meio da tecnologia incansável das mídias ópticas. Há uma complexidade inédita nesse pensamento, delineada a partir do acúmulo das reflexões ensaísticas que acompanhamos ao longo do filme e pela severa racionalidade do comentário, que aponta para o condicionamento psicotécnico dos operários, enquadrados por uma estrutura mais ampla de vigilância e controle. 0 filme dos Irmãos Lumière, $A$ saída dos operários da fábrica (1895), só vai retornar mais uma vez, ao final do filme, porém sem o acompanhamento reflexivo da voz em off. Nesse momento, nessa última visualização, teremos a chance de perceber as imagens do primeiro cinema de outra maneira: nossos olhos foram abertos para a experiência sensível de outros componentes da imagem e para a compreensão de efeitos de sentido que eles produzem.

Como no método dialético de Brecht, influência central para o trabalho de Farocki, o cinema é convocado a re-montar as relações entre gestos, imagens e ideias, a fim de "[...] transformar e multiplicar seus próprios meios para aprender algo sobre o mundo e agir sobre ele" (DIDI-HUBERMAN, 2009, p. 191, tradução nossa). Há, nesse sentido, uma forte perspectiva pedagógica, destinada a produzir deslocamentos no espectro do visível, propiciar desvios de posições ou sentidos, a fim de provocar no espectador a possibilidade ativa de assumir um ponto de vista outro sobre as coisas. "Ensinar a ver abismos onde há lugares comuns": essa será a tarefa pedagógica por excelência do cinema de Farocki, para remeter à formulação de Karl Kraus (1932).

Há, contudo, um elemento importante na última convocação do curta dos Lumière, situada no encerramento do filme. Embora exibida sem acompanhamento sonoro, ela é precedida por uma significativa série de imagens de arquivo e reflexões em off, que questionam o aperfeiçoamento do realismo na pintura. Um aperfeiçoamento que desembocaria, como sabemos, na conversão da arte representativa em tecnologia óptica, com todas as rupturas e repercussões que esse processo implica. Em algum momento, 
portanto, quando não era mais possível acreditar na perfeição (ilusória) das tintas, na realidade concreta daquele mundo fabricado pelo pintor, daquela arte milenar de imitar a natureza, inventou-se o cinema. Supostamente, este seria um meio mais apto para captar a forma legítima do real, sua manifestação inconteste, devido à sua condição de máquina autônoma, ao elevado grau de objetividade inerente ao seu funcionamento técnico.

Existe, é claro, nessa nova objetividade, uma perversão sutil da relação entre a imagem e o mundo. Como Friedrich Kittler (2010) afirma, seguindo as reflexões de Hugo Münsterberg - o primeiro teórico da história do cinema -, se as artes tradicionais buscavam uma relação de fidelidade ou subversão mimética diante do mundo, que não perdia com isso a sua primazia, se as próprias “[...] mídias tecnológicas emergiram no século dezenove a partir da pesquisa psicológica e fisiológica sobre um objeto humano bastante empírico e não mais transcendental" (KITTLER, 2010, p. 175-176, tradução nossa), o cinema, por sua vez, instaurava uma nova situação:

Quando Münsterberg escrevia em 1916, [...] essas mídias tecnológicas eram perfeitas e poderiam, por sua vez, fornecer modelos para a psicologia e a fisiologia. Se a atenção subliminar é nada mais do que um truque cinematográfico, então os humanos podem ser fabricados e otimizados, em vez de serem ainda mais idolatrados idealisticamente. 0 personagem cineasta de Pynchon estava de fato enganado quando ofereceu a confortável garantia de que não vivemos por completo no cinema. Na realidade técnica, o cinema experimental científico, acima de tudo, muda as realidades da própria vida. Pessoas trabalhando na linha de montagem executam movimentos ensinados a elas por um filme (KITTLER, 2010, p. 176, tradução nossa).

Os rendimentos da combinação entre homem e máquina constituem, de fato, um tópico recorrente na obra de Farocki. Em Imagens do mundo e inscrições da guerra (1988), que de certa forma é um filme sobre as lógicas manual e automática (do olhar), vemos planos de trabalho relacionados a máquinas: o desenho industrial, associado às técnicas de medição e à visão em perspectiva, os discos giratórios da caldeiraria, os braços robóticos do setor automobilístico etc. O mesmo ocorre em Como se vê (1986), que dedica muitas sequências à substituição e à readequação do trabalhador, decorrentes da introdução das máquinas nas fábricas, com especial atenção ao setor têxtil. Em Reconhecer e perseguir (2003), o mesmo gesto de trabalho, antes e depois de um "aprimoramento técnico" na máquina, é mostrado em duas telas simultaneamente, enquanto a voz off tece reflexões 
sobre a aceleração do trabalho operário na linha de montagem. Em todos esses exemplos, Farocki está preocupado em analisar as mutações do humano no contato com ambientes tecnológicos típicos do capitalismo tardio.

A saída dos operários da fábrica (1995) começa com a reprodução do "primeiro filme da história apresentado no cinema", continua com o rastreamento do tema dos trabalhadores saindo do local de trabalho - "com o máximo de variantes possíveis" - e desemboca na questão extremamente atual dos efeitos materiais da técnica sobre os seres humanos. Ao longo da montagem, que decompõe, analisa e recombina os movimentos dos operários, encontramos instigantes reflexões sobre a maneira como eles se manifestam. Para tanto, o filme desdobra múltiplas cenas do trabalho, como as figuras da greve, as derivas da fábrica, os mecanismos de vigilância, as infiltrações de ladrões, até colocar em questão a própria interferência do cinema sobre a fábrica e o mundo social, pautada pela lógica da vigilância e do controle. Não estamos mais presos ao conteúdo estrito das imagens convocadas pela obra, que abrem espaço para um pensamento sobre as condições de aparição da própria imagem. Farocki combina a especificidade mecânica da representação cinematográfica com os modos de convocação do corpo na modernidade, sobretudo no que diz respeito à repetição e à regulação dos gestos na linha de montagem (Cf. CRARY, 2012, 2013) Da mesma forma que já havia feito em outros filmes, como Imagens da prisão (2000), ele constrói um pensamento peculiar sobre os modos de existência e de normatização dos corpos nos espaços modernos de existência.

Farocki, porém, indica um segundo problema fundamental que orienta as imagens do trabalho. Ele concerne ao desaparecimento da imagem do operário, à sua desintegração crescente enquanto sujeito coletivo, em correspondência à invisibilidade crescente de tudo o que se passa no espaço interior da fábrica, demasiado protegido para ser filmado: a câmera dos Lumière, responsável pela aparição dos movimentos dos operários, é impossibilitada de adentrar os portões do galpão. É justamente isso que permite que os filmes só comecem quando termina o expediente. Em "Filmar operários", ao comentar o filme de Roberto Gerwitz e Sérgio Toledo, Braços cruzados, máquinas paradas, de 1979, Jean-Claude Bernardet (2003) afirma que o portão da fábrica é uma verdadeira fronteira para a câmera, e lembra daquele aviso ("No trespassing") nas grades do palácio do magnata da imprensa, Charles Foster Kane.

Kittler (2010) conta, mais de uma vez, uma anedota famosa segundo a qual, com a invenção da fotografia, Oliver Wendell Holmes Sr. teve a brilhante ideia de destruir todas as 
obras de arte (usando pólvora, por exemplo) imediatamente após elas terem sido fotografadas. "E, desde as duas grandes guerras mundiais, uma ideia ainda mais brilhante emergiu, de fotografias de reconhecimento feitas por aviões ou satélites que contribuem, no fim, para a destruição sistemática do objeto fotografado" (KITTLER, 2010, p. 132). Esse é justamente o tema principal de Imagens do mundo e inscrições da guerra (1988): o vínculo secreto entre a fotografia e a destruição. Tema similar ao explorado filosoficamente por Jacques Derrida (2001) em seu livro Mal de arquivo. Se aplicarmos essa lógica, figurativamente, às imagens cinematográficas do operariado, podemos nos questionar se essa primeira câmera apontada para a fábrica não anunciava, por antecipação, o desaparecimento eventual de certa força de trabalho manual do imaginário fílmico (e fotográfico).

Ora, Farocki mostra bem de que modo essa força de trabalho, que se torna socialmente visível com as imagens da saída da fábrica, constitui uma manifestação instável, sujeita, antes de mais nada, à sincronização coletiva exigida pelas estruturas da fábrica, sejam elas de tempo, isto é, pelos horários de chegada e saída, sejam elas de espaço, pelos limites dos muros e portões. Uma sincronização que se duplica, ademais, na própria estrutura das mídias de massa, das quais o cinema é talvez a manifestação mais emblemática ao longo do século XX, servindo de modelo, posteriormente, para a televisão e o computador. Uma sincronização que impede, no fundo, uma união coletiva mais potente, uma potência de aparição comunitária, de confrontação da violência social. Com exceção de alguns raros momentos de greve, na maior parte fantasiosos, a permanência dos trabalhadores em grupo na tela não dura mais do que a passagem pela cancela, após a qual sua imagem como corpo coletivo, de trabalhadores, se desintegra. Como afirma Nicole Brenez: “[...] analisando a sucessão e o detalhe dos planos dos Lumière, Farocki revela o programa das opressões e resistências que vão estruturar o século XX" (BRENEZ, 2016, p. 73-74, tradução nossa).

Nesse movimento de análise (ou diagnóstico, como prefere Brenez, 2016), encontramos uma nova faceta da montagem farockiana, que se abre para os efeitos materiais da imagem sobre os próprios suportes midiáticos. Também no filme 0 gesto das mãos (1997), o estudo das técnicas de normatização inscritas nas imagens - que determinam, de modo geral, os gestos humanos possíveis, bem como as maneiras de olhar para eles - adquire a forma de um meta-filme, composto predominantemente por materiais extraídos de outras obras audiovisuais. A partir delas, o cineasta indaga acerca das 
concepções de trabalho cristalizadas em pelo menos duas categorias básicas: a saída da fábrica, filmada pelos irmãos Lumière em 1895, uma das cenas fundadoras de certa tradição da imagem em movimento; e as mãos humanas, um dos signos icônicos mais intensamente explorados pela técnica do close-up, de Griffith a Bresson. 0 olhar para as imagens, portanto, se confunde com o olhar para o próprio cinema, cuja história é inseparável das tecnologias de controle que acarretam, elas mesmas, formas específicas de capturar o olhar. ${ }^{4}$

\section{Interseções midiáticas}

Em uma televisão de tubo antiga, típica da década de 1990, filmada em close, vemos imagens de pessoas reunidas em uma praça. Trata-se de um palanque oficial do líder do governo romeno, o ex-presidente Nicolae Ceaușescu, que fazia, na ocasião, o seu derradeiro discurso público. A câmera está inquieta, como se captasse alguma vibração diferente no ar, como se o olhar da lente, seus tremores, seus movimentos, traíssem no sujeito que filma uma emoção mais forte do que o programa oficial transmitido pela emissora estatal. Assim, ela logo se afasta da televisão com um zoom out, e continua a oscilar pelo cômodo, ao fundo do qual há uma cortina semitransparente - um véu da verdade que irá se revelar? 0 cinegrafista, então, caminha até a janela e vira a câmera para a rua, para ver se os distúrbios continuam, se há novos desdobramentos, como explica a voz em off de uma mulher. Um corte brusco será usado, enfim, para trazer uma nova imagem televisiva, na qual a apresentadora da TVR (Televiziunea Romana), desta vez ocupando a tela toda do filme, agradece aos espectadores por terem acompanhado a "grande concentração popular na Praça da República da Capital".

Sabemos, desde o início da narrativa, que o tema abordado por Videogramas de uma revolução (1992), dirigido por Farocki e Andrei Ujică, é de disputa, de dissenso, de turbulência social. Minutos antes, os realizadores já haviam mostrado uma mulher que, ferida pela polícia, é carregada para um leito de hospital no qual, entrevistada pela TV, clama pelo fim do regime de Ceaușescu. E haviam mostrado, também, o momento em que o discurso oficial do presidente da nação fora interrompido para dar lugar a uma tela vermelha, justamente quando a emissora do governo era ocupada pelos manifestantes da

\footnotetext{
${ }^{4}$ Cabe lembrar que não é apenas no ambiente estrito da fábrica que Farocki investiga essas relações de poder e controle. Em Leben - $B R D$, de 1990, ele observa os modos de padronização do comportamento humano em diferentes ocupações fundamentais na Alemanha Oriental, como policiais, parteiras e agentes de seguro.
} 
oposição. Há, portanto, uma variação de suportes e formatos, de fontes oscilantes, registros que Farocki e Ujică organizam meticulosamente no fluxo da montagem, com o acréscimo cirúrgico de uma camada discursiva textual composta por comentários explicativos bastante sutis, destinados a auxiliar na elaboração do conjunto. Essa variação nos mostra, prioritariamente, uma querela que se desdobra em correspondência com os próprios dispositivos midiáticos convocados. No filme, há pelo menos três camadas de pontos de vista imagéticos que se cruzam, se misturam, se chocam para a construção histórica desse acontecimento político: a imagem televisiva (em especial, a transmissão oficial do canal governamental); a imagem videográfica (com destaque para os registros amadores que subvertem a hegemonia comunicacional do Estado); e a imagem cinematográfica (que organiza e reconstrói as duas camadas anteriores conjuntamente, no mesmo fluxo audiovisual).

Retomemos, neste ponto, a conclusão de A saída dos operários da fábrica (1995): o cinema, na sua condição de tecnologia óptica, traz uma diferença fundamental em relação ao mundo, quando comparado com as artes representativas tradicionais, como a pintura. Não se mais trata de fabricar um olhar que se aproxime mimeticamente da natureza, que conjugue a expressividade criativa com a possibilidade de revelar a essência do real. No cinema, arte de fotografar tecnicamente o movimento, a realidade visível é duplicada sob a forma de imagem, como um mundo espelhado, como um embalsamamento do tempo, para usar a conhecida formulação de André Bazin (2014). Mais importante ainda, porém, é o fato dessa imagem (cinematográfica) poder se reproduzir ao infinito, com a garantia de que a cada vez que isso acontece, um espectador qualquer estará olhando para um objeto visualmente idêntico às visualizações anteriores ou subsequentes, feitas por ele ou por outros espectadores. Sob a égide do cinema, um número massivo de pessoas pode ser afetado pelas mesmas imagens, o que acarreta toda uma nova estrutura de consciência e memória para os sujeitos conectados. Como escreveram Adorno e Horkheimer em relação à indústria cultural, cujo denominador maior era, sem dúvida, o cinema hollywoodiano:

Ao subordinar da mesma maneira todos os setores da produção espiritual a esse fim único - ocupar os sentidos dos homens da saída da fábrica, à noitinha, até a chegada ao relógio do ponto, na manhã seguinte, com o selo da tarefa de que devem se ocupar durante o dia - essa subsunção realiza ironicamente o conceito de cultura unitária que os filósofos da personalidade opunham à massificação (ADORNO; HORKHEIMER, 2006, p. 108). 
Pela primeira vez na história, as consciências humanas podem ser sincronizadas em escala planetária, e também os desejos, os imaginários, as identidades individuais ou coletivas, tudo isso que Farocki havia percebido, por exemplo, na figura do operário, cuja existência é programada a partir dos cruzamentos primários da câmera com o espaço da fábrica. Existem, porém, etapas subsequentes nesse processo de sincronização das consciências em larga escala, que se concentram, a princípio, no meio televisual. Como afirma Stiegler (2011):

A televisão acrescenta [ao cinema] dois efeitos fotográficos e cinematográficos novos:

I. Na medida em que é uma técnica de tele-difusão, a televisão permite que um público massivo assista simultaneamente ao mesmo objeto temporal de qualquer localização; mais ainda, ela acarreta a construção de mega-objetos temporais, as grades de programação pelas quais vários objetos temporais audiovisuais são conectados para formar uma rede (a "rede televisiva");

II. Na medida em que é uma técnica de transmissão "ao vivo", ela permite que esse público, coletiva e universalmente, vivencie qualquer acontecimento no momento da sua ocorrência e, assim, permite a difusão de um objeto temporal ao vivo. A final da Copa do Mundo jogada em 12 de julho de 1998, na França, a transmitida ao vivo, é um caso exemplar - é a "recepção imediata" do acontecimento que o torna o acontecimento (STIEGLER, 2011, p. 33-34, tradução nossa).

Sabemos que Farocki realizou uma importante instalação sobre outra final da Copa do Mundo, a de 2006, na Alemanha, disputada entre Itália e França, mas não é nosso objetivo, por ora, nos determos nos sentidos dessa obra. Se fizemos, até aqui, esse pequeno desvio pela filosofia de Adorno e Horkheimer (2006) e de Stiegler (2011), foi para iluminar o pensamento midiático do cineasta alemão em Videogramas de uma revolução (1992). Farocki, como poucos cineastas, tem uma profunda consciência do que está em jogo nessa defasagem - para usar o termo sugerido por André Brasil (2008), - entre uma imagem televisiva e uma câmera amadora de vídeo. Naquele momento de dissenso e de violenta ruptura social, ele sabe que o destino ulterior de toda transmissão televisiva oficial, de toda programação, seria o de restabelecer um ponto de vista unívoco, aplainado, solidificado, impedindo toda visibilidade ambígua no olhar e na percepção de mundo dos espectadores. Sincronizando os acontecimentos com uma mesma narrativa programada, lapidada, pacificada, a televisão aniquila a possibilidade de uma imagem destoante, de uma imagem nova. Como afirma Raymond Bellour (2002), há duas maneiras das artes da imagem lidarem 
com o fluxo televisivo: "Ou a televisão se submete a seu próprio fluxo, experimenta seu próprio fluxo como uma lei incontrolável. Ou ela resiste ao fluxo. [...] Colocando-se no interior, na televisão como instituição do fluxo. Ou fora dela" (BELLOUR, 2002, p. 62, tradução nossa).

É justamente isso que está em jogo no breve plano com a apresentadora da TVR, quando ela encerra a transmissão enganosamente, falaciosamente, sem fornecer informações sobre o que de fato ocorria. 0 vídeo vem, então, disputar essa narrativa arbitrária, inserindo fissuras explosivas onde a televisão escolhera, antes, preservar uma suposta continuidade do olhar. A arte do vídeo é aquela que "impõe silêncio à televisão" (BELLOUR, 2002, p. 61, tradução nossa).

Farocki mostrará como a estação de TV se transforma no palco da revolução desencadeada no país, sediando um vasto feixe de interesses e urgências estendidos em torno do poder técnico-midiático do aparelho. Emblemática, nesse sentido, é a reunião com o diretor da emissora, na qual as lideranças do movimento preconizam seu papel indispensável - ao lado do exército - para realizar a comunicação "com todo o país" e garantir a ordem pública nesse momento de tensão: "Precisamos da televisão". As lideranças do movimento tentavam, ao mesmo tempo, garantir que os manifestantes não danificassem a estrutura do edifício, com seus equipamentos: "Temos que descer para o térreo, senão vão destruir tudo. A televisão é propriedade nossa". Afinal, como controlar um evento dessa magnitude sem o apoio de um aparato midiático para enquadrá-lo adequadamente, para defini-lo e transmiti-lo em larga escala?

A tomada de poder por parte dos manifestantes não estaria refletida, assim, na tomada do próprio aparato televisivo e do ponto de vista por ele disseminado? Mas as imagens de vídeo, aparentemente onipresentes, colocam até mesmo esse pressuposto em xeque, mostrando instantes depois como o diretor televisivo, junto a outras pessoas, arrasta o porta-voz dos manifestantes para uma sala fechada: "Tenho algo importante para te dizer". Com a câmera de fora, desligada, é a voz em off da narradora que nos ajuda a pensar e a resgatar esse momento: "O diretor afirma que queria discutir detalhes técnicos com o visitante. E o inquilino afirma que o diretor lhe falou para não se meter, pois as cartas já estavam dadas, o jogo já estava rolando". Quem está, de fato, no controle? Quem monta esse programa que assistimos na tela, cujas imagens as câmeras profissionais e amadoras reunidas por Farocki parecem decompor didaticamente em história? Mais uma vez, não há 
resposta: as operações de montagem preservam a opacidade que subsiste ao conjunto das perspectivas (midiáticas), com suas camadas e lacunas.

Em todo caso, ao sairmos dos registros das tomadas externas dos cinegrafistas amadores para entrar nos registros feitos pelos próprios manifestantes que ocuparam a emissora, vemos um novo espaço complexo de disputa e negociação, instaurado a partir da tomada do poder midiático. A todo momento, o que fica patente é esse desejo da montagem (cinematográfica) de analisar as imagens de arquivo (televisivas, videográficas), a fim de restabelecer uma pluralidade de pontos de vista, sem perder de vista a construção de um tecido histórico tangível. Formalmente, Farocki atua entre a progressão dos acontecimentos e a fragmentação dos olhares, deixando claro que a continuidade dos planos-sequência está sempre sujeita aos choques da organização da montagem.

Em outras palavras, a profusão de pontos de vista por ele convocados, mesmo que muitos deles possuam uma "aparência de real", reintroduz no discurso certa zona de opacidade e de ambiguidade, impedindo que o acontecimento abordado se feche em uma única visão totalizante, mostrando que, no fundo, toda narrativa é resultado de uma construção. A voz em off afirma, perto do final do filme: "O cinema existe para tornar a história visível”. E, para Farocki, importa mais pensar como a história se constrói, por meio dessa ferramenta analítico-epistemológica que é o cinema, do que destrinchar o que exatamente ela constrói. E ela se constrói, talvez, por meio de um sem fim de disputas midiáticas, de perspectivas variadas e repetições (hoje em dia há novos dispositivos na querela, como as redes sociais, os telefones celulares, o WhatsApp). Como afirma André Brasil (2008):

A voz em off que atravessa o filme é econômica, descritiva e menos analisa os fatos do que sublinha um e outro momento, uma e outra cena. Às vezes, a repetição dos fragmentos (ou sua suspensão) se torna uma estratégia aliada ao texto. É assim que, juntamente com a história que se costura com as imagens, o ensaio costura o pensamento: o dos cineastas e o nosso. Pensamento ao vivo, em direto, colado aos acontecimentos, como o são as imagens do mundo hoje. Mas, um pensamento que consegue se produzir também como diferença, como escritura, como recriação, mesmo que seja na distensão de um lapso do instantâneo (BRASIL, 2008).

Esse caráter de escritura, portanto, o filme tentará evidenciar por meio de momentos estratégicos, quando, por exemplo, exibe a transmissão da demissão do primeiroministro na varanda da praça. Farocki faz questão de dar a ver a mesma cena três vezes, 
registrada por três câmeras diferentes, só para depois, finalmente, mostrar que o ato da demissão precisou ser reencenado, regravado, pois da primeira vez a TV não estava pronta para gravar. Entre a primeira e a segunda encenação, tudo muda: o primeiro-ministro, que antes se demitira rapidamente, saindo da cena despercebido, agora apresenta uma postura autoconfiante, oferece um discurso mais elaborado, não obstante carregado de demagogia. Da segunda vez, os manifestantes o chamam de mentiroso, e ele precisa ser escoltado para fora da varanda. Há também, em outra ocasião, os "problemas técnicos" da transmissão que, verdadeiros ou não, definem a visibilidade (ou não) das pessoas que estão sendo mostradas pelas transmissões da televisão.

Se, como afirma Didi-Huberman (2018, p. 116), "Farocki considera cada aparelho, cada imagem técnica, um verdadeiro campo de conflitos", o trabalho crítico realizado pela montagem se dá no interior das formas expressivas próprias das diferentes mídias e dispositivos, que o autor convoca para desmontá-los em sua estrutura e desconstruir seus efeitos de sentido. Para bem entendermos a singularidade dessa investigação imagéticoensaística farockiana, devemos notar como os elementos associados à condição tecnocientífica da humanidade são apanhados e diagnosticados sempre no domínio imanente das imagens, nos seus mais diferentes contextos e dispositivos técnicos (do cinema à publicidade, das câmeras de vigilância aos simuladores militares, sem esquecer dos videogames). Em Farocki, a elaboração política nunca perde de vista uma contraparte de elaboração estética, isto é, uma inscrição propriamente imagética - sob várias modalidades - do pensamento.

\section{Referências}

A SAÍDA dos operários da fábrica (Arbeiter verlassen die Fabrik). Direção: Harun Farocki. Alemanha, Harun Farocki Filmproduktion, 1995. video-BetaSp (36 min.), col. e b/w, 1:1,37.

ADORNO, Theodor W.; HORKHEIMER, Max. Dialética do esclarecimento: Fragmentos filosóficos. Rio de Janeiro: Jorge Zahar, 2006.

BAZIN, André. Ontologia da imagem fotográfica. In: 0 que é o cinema? São Paulo: Cosac \& Naify, 2014, p. 27-35.

BELLOUR, Raymond. L'entre-images: Photo. Cinéma. Vidéo. Paris: Éditions de la Différence, 2002. 
BELLOUR, Raymond. La querelle des dispositifs: Cinéma, installations, expositions. Paris: P.O.L. Trafic, 2012.

BERNARDET, Jean-Claude. Cineastas e imagens do povo. São Paulo: Companhia das Letras, 2003.

BRAÇOS cruzados, máquinas paradas. Direção: Roberto Gerwitz e Sérgio Toledo. Brasil, 1979. $16 \mathrm{~mm}$ (76 min.), col.

BRASIL, André. Ensaio de uma revolução. Cinética, [S.l.], set. 2008. Disponível em: http://www.revistacinetica.com.br/videogramas.htm. Acesso em: 22 mai. 2019.

BRENEZ, Nicole. Harun Farocki e a gênese romântica do princípio de crítica visual. In: Festival internacional do cinema documentário. Goiânia: Fronteira, 2014.

BRENEZ, Nicole. Contre-attaques: Soubresaults d'images dans l'histoire de la lutte des classes. In: DIDI-HUBERMAN, Georges (ed.). Soulèvements. Paris: Gallimard/Jeu de Paume, 2016, p. 73-74.

COMO se vê (Wie man sieht). Direção: Harun Farocki. Alemanha, Harun Farocki Filmproduktion, 1986. 16mm (72 min.), b/w e Eastmancolor, 1:1,37.

CRARY, Jonathan. Suspensões da percepção: Atenção, espetáculo e cultura moderna. São Paulo: Cosac Naify, 2013.

CRARY, Johnatan. Técnicas do observador: Visão e modernidade no século XIX. Rio de Janeiro: Contraponto, 2012.

DANEY, Serge. A rampa. São Paulo: Cosac Naify, 2011.

DERRIDA, Jacques. Mal de arquivo: Uma impressão freudiana. Rio de Janeiro: Relume Dumará, 2001.

DIDI-HUBERMAN, Georges. Quand les images prennent position: L'oeil de l'histoire, 1. Paris: Les Éditions de Minuit, 2009.

DIDI-HUBERMAN, Georges. Remontagens do tempo sofrido: O olho da história, II. Belo Horizonte: Editora da UFMG, 2018.

ELSAESSER, Thomas. Political filmmaking after Brecht: Farocki, for example. In: Harun Farocki: Working on the sight-lines. Amsterdã: Amsterdam University Press, 2004, pp. 133153.

FAROCKI, Harun. Desconfiar de las imágenes. Buenos Aires: Caja Negra, 2013.

FAROCKI, Harun; SILVERMAN, Kaja. Speaking about Godard. Nova York: New York University Press, 1998.

FOUCAULT, M. Vigiar e punir: Nascimento da prisão. Petrópolis: Vozes, 1987. 
IMAGENS DA PRISÃO (Gefängnisbilder). Direção: Harun Farocki. Alemanha, Harun Farocki Filmproduktion, 2000. vídeo (60 min.), video col. and b/w.

IMAGENS DO MUNDO e inscrições da guerra (Bilder der Welt und Inschrift des Krieges). Direção: Harun Farocki. Alemanha, Harun Farocki Filmproduktion, 1988. 16mm (75 min.), col. e b/w, 1:1,37.

INTERFACE (Schnittstelle). Direção: Harun Farocki. Alemanha, Harun Farocki Filmproduktion, 1995. 16mm (23 min.), video-BetaSp (projeção dupla), col., 1:1,37.

KITTLER, Friedrich. Optical media: Berlin lectures 1999. Cambridge: Polity Press, 2010.

KRAUS, Karl. Die sprache. Die Fackel, [S.l.], v. 34, n. 885-887, p. 3-4, Dez. 1932.

MCLUHAN, Marshall; FIORE, Quentin. The medium is the massage: An inventory of effects. Londres: Penguin Books, 2007.

MCLUHAN, Marshall. Understanding media: The extensions of man. Cambridge: MIT Press, 1994.

O GESTO das mãos (Der Ausdruck der Hände). Direção: Harun Farocki. Alemanha, Harun Farocki Filmproduktion, 1997. video-BetaSp (30 min.), col., 1:1,37.

RECONHECER e perseguir (Erkennen und Verfolgen). Direção: Harun Farocki. Alemanha, Harun Farocki Filmproduktion, 2003. vídeo (58 min.), col.

STIEGLER, Bernard. Time and technics, 3: Cinematic time and the question of malaise. Stanford: Stanford University Press, 2011.

TEMPOS modernos (Modern times). Direção: Charlie Chaplin. Estados Unidos, United Artists, 1936. $35 \mathrm{~mm}$ (87 $\mathrm{min}$.$) , b/w, 1:1,37.$

THE KILLERS. Direção: Robert Siodmak. Estados Unidos, Mark Hellinger Productions, 1946. $35 \mathrm{~mm}$ (103 $\mathrm{min}$.), b/w, 1:1,37.

VIDEOGRAMAS de uma revolução (Videogramme einer Revolution). Direção: Harun Farocki. Alemanha, Harun Farocki Filmproduktion, 1992. Vídeo, transferido para 16mm (106 min.), col., 1:1,37. 


\title{
Recomposing media: Harun Farocki's visual thinking
}

\begin{abstract}
Using a diversity of materials, German filmmaker Harun Farocki made a series of vigorous investigations about technical images and their effects on human life. We can place his thoughts among leading 20th-century media and technique philosophers such as Friedrich Kittler and Jonathan Crary, and control technologies philosophers such as Michel Foucault. Focusing on the normative effects and intersections of media technologies, the artist creates unique films in which specific cultural elements or contexts connect through montage to the wider circuits that surround them. In fact, such a process of cinematic thinking allows him to continually compose and recompose images and the media in order to achieve a broader understanding of their mechanisms. This article analyzes the films Workers exiting the factory (1995) and Videograms of a revolution (1992) in order to understand better Farocki's visual thinking.
\end{abstract}

\section{Keywords}

Farocki. Montage. Media. Cinema. Technics.

Recebido em 23/05/2019

Aceito em 01/07/2019 